\title{
Heat recovery potentials and technologies in industrial zones
}

\author{
Feng Huang ${ }^{\mathrm{a}, \mathrm{b},{ }^{*} \text {, Jie Zheng }}{ }^{\mathrm{a}}$, J.M. Baleynaud ${ }^{\mathrm{b}}$, Jun Lu ${ }^{\mathrm{a}}$ \\ a Key Laboratory of the Three Gorges Reservoir Region's Eco-Environment, Faculty of Urban Construction and Environmental Engineering, Chongqing \\ University, Chongqing, 400045, PR China \\ b PHASE Laboratory, University Paul Sabatier, Toulouse, 31400, France
}

Keywords:

Industrial waste heat

Heat recovery technologies

Industrial zones

Sustainable development

Energy efficiency

\begin{abstract}
a bstract
Low-temperature industrial waste heat is an important heat source for industrial processes and utility services to reduce the consumption of fossil energy as well as lower the risk of global warming. In this article, a review of waste heat recovery e a critical solution of waste energy disposal is made in order to show the current status of heat recovery potentials and the possible technologies used industries. The concept of industrial waste heat is defined, potential sources of waste heat from industries are identified and conclusions are drawn. Then, the technologies available for waste heat recovery are illustrated in terms of heat pumps, heat exchangers, heat pipes, boilers, refrigeration cycles, power cycles and heat storage according to the transfer mode of waste heat within the recovery process. The waste heat opportunities both in developed and developing countries are discussed in order to determine the possible benefits of heat recovery as well as to make a general survey of the development of heat recovery technologies globally. Research of typical applications of industrial waste heat recovery in Asian countries and especially in China is overviewed to show the performance of this engineering in practice.
\end{abstract}

\section{Introduction}

Energy is the driving force of the development of global and national economies, economic losses globally due to over-exploitation and over-use of energy. Even so, the overall energy consumption has never been cut by lowering the energy for manufacturing and living requirements, thus it is necessary to improve the energy efficiency rather than reduce basic energy for production. Nowadays, industry accounts for about a third of the world's total energy consumption and $36 \%$ of $\mathrm{CO}_{2}$ emissions [1]. It was reported by IEA that, based on the level of 1971, industrial energy consumption had increased by $61 \%$ in 2004 , caused by the rapidly increasing energy demand of developing countries. In practice, the energy cannot be totally converted into useable heat or power in industrial processes due to the limited conversion efficiency of the equipment. Ideally, it would be most profitable to recover the waste heat as fully as possible without extra cooling or heating from an exterior system [2]. At the beginning of industrialization, industrial activities were restricted to isolated individual plants and each plant was generally equipped with a separate energy and material supply system. Since 1950, the practice of industrial parks was firstly launched in the United States, one well known example being Silicon Valley. The characteristics of an industrial park differ from independent industries or factories in that all plants located in the same zone could share a common energy system and infrastructure, which may reduce the construction investment and operational costs [3,4]. As industrial systems evolved and became upgraded, along with the energy efficiency and environmental protection requirements, the concept of Ecoindustrial Park emerged and has been rapidly and vigorously applied to the design and construction of industrial parks [5e8]. Although most industrial parks and industrial symbiosis practices have been successful, some installations suffered from suspended operation for consolidation, or production shut down to improve environmental standards (domestic and overseas) or due to the global effects of world economic restructuring [9]. However, based on the current developing status of industry, substantial opportunities should be seized to improve global energy efficiency and energy utilization, particularly in industrial parks to fulfill the responsibilities of environmental protection and the achievement of economic development.

Thus, sustainable development in industry should be achieved by improving energy supply, energy consumption, the amount of waste energy and the conditions of energy rejection. Admittedly, exploiting renewable energy instead of fossil fuels is an efficient way to relieve the environmental burden and energy crisis, contributing to social development. In [10], a comprehensive overview was made to illustrate solar technologies, classified according to the processes of photovoltaic and concentrating solar power generation. More importantly, the influence of using solar energy was evaluated according to current research knowledge in order to provide a reference for evaluating the feasibility and risks of solar technology in the desired areas. In [11], the available wind technologies were discussed and an overview of the performance of wind energy in terms of economic, technical, social and environmental challenges was made to show the potential of wind energy deployment. In fact, hybrid renewable energy systems are more popular in practice compared to the use of a single energy source [12]. Especially in terms of power generation, combining several types of renewable energy together could maximize efficiency by optimizing the configuration [13]. Besides, renewable energy systems with the help of waste heat recovery could be more effective in both improving energy efficiency and relieving environmental pollution [14,15]. Therefore, the deployment of renewable energy has boosted social sustainability by playing the role of energy supply. However, waste heat recovery is not only a source of useable energy, but also an effective way to recycle waste energy to lower gas emissions and mitigate global warming.

In this article, a review of waste heat recovery e a critical solution of waste energy disposal e is made in order to show the current status of heat recovery potentials and the technologies available in industry. To begin with, the concept of industrial waste heat is defined, potential sources of waste heat in industry are determined and a conclusion is reached. Then, the technologies available for waste heat recovery are classified as heat pumps, heat exchangers, heat pipes, boilers, refrigeration cycles, power cycles and heat storage according to the mode of transfer of waste heat within the recovery process. Moreover, the opportunities for waste heat recovery both in developed and developing countries are discussed in order to determine the benefits of heat recovery as well as to carry out a general survey of the development of heat recovery technologies globally. Finally, typical research of the situation of industrial waste heat in Asian countries especially in China is overviewed to show the performance of engineering practices. 


\subsection{Definition of waste heat}

When considering the reuse of waste heat in industry, how waste heat is identified as a potential alternative to primary energy is important for selecting the suitable waste heat recovery technologies. There is a general idea of "waste heat" that it can be regarded as the heat emitted directly into the environment [16]. In an industrial zone where high-grade waste heat has already been reused within the processes and across the industries, most waste heat of less than $200 \quad \mathrm{C}$ is still discarded into the atmosphere [20]. But in fact, there are avoidable and unavoidable waste heats in industrial processes. Due to the restrictions of the second law of thermodynamics and the technologies available, unavoidable waste heat cannot be converted into an avoidable form and the recovery yield of avoidable waste heat depends primarily on the system design and operation. In order to reduce global warming, more attention should be paid to waste heat recovery, so it is important clearly define what waste heat really is. According to the type of carrier medium, the waste heat can be recovered from flue gas, cooling fluids and exhaust steam [17]. Furthermore, exhaust steam is defined as Low Pressure steam (below saturation temperature of $180 \mathrm{C}$ ), Medium Pressure steam (saturation temperature from $180 \mathrm{C}$ to $250 \mathrm{C}$ ) and High Pressure steam (above saturation temperature of $250 \mathrm{C}$ ) in ref. [18] in order to better price the steam for calculating the recovered utility value. In the implementation plan of a waste-heat driven DH (District Heating) project, low-grade waste heat refers to liquid and exhaust steam at less than $100 \mathrm{C}$, flue gas at less than $200 \mathrm{C}$, sensible heat of the solid above $400 \quad \mathrm{C}$ and other medium/high-grade waste heat sources not to be fully recovered due to scattered heat sources and high recovery cost [19].

\subsection{Sources of industrial waste heat}

To achieve better performance of heat recovery technologies, it is important to explore the stable and ample waste heat sources for activating and supporting the operation of heat recovery systems. Generally speaking, there are many unexploited low-grade waste heat sources including flue gas, exhaust steam and cooling water in which temperature levels normally fluctuate. In [18], waste heat was derived from the cold end of the process with the heat being ejected into cold utilities, mainly air and cooling water. Besides, steam at different temperatures from recovered waste heat could generate hot utilities in one plant for transfer to the utility system of another plant at the appropriate level in order to offset the need for utility generation in the plant.

The sustainability of the waste resource is also very important to keep the waste energy recovery technology operating in the long term. Generally, waste heat can be reused either internally or externally in the industrial energy process. For the purpose of internal usage, waste heat recovery will increase the energy efficiency of the industrial processes. While for external usage, waste heat recovery may provide the energy motivation for other industrial processes and utility services, whose requirements of energy can be satisfied by low grade energy. So, the target of waste heat recovery should be detailed to maximize internal heat recovery to improve energy efficiency within the main industrial system and to identify the heat recovery potential externally for other energy requirements with the consideration of economic benefit.

\subsection{Industrial heat recovery technologies}

To capture and reuse the low-temperature waste heat produced by industrial processes and utilities, the suitability and feasibility of waste heat recovery technologies have been analyzed and evaluated as possible solutions for recovering low temperature waste heat, which has been reported as: heat pump, heat exchanger, heat pipe, boiler, refrigeration cycle, power cycle and heat storage. In [17], waste heat recovery was divided into active and passive technologies according to usage planned. Hence, if recovered heat is used directly at the same

or a lower temperature, the technology is so-called "passive", and "active" when the heat is converted into other forms of energy or is used at higher temperature. As a result, the technologies of heating and cooling production and power generation are regarded as typical active heat recovery strategies, while heat exchangers and thermal energy storage are regarded as typical passive heat recovery strategies. However, in this study, waste heat recovery is divided into direct and indirect recovery technologies without considering temperature level, only considering waste heat treatment mode, i.e. whether waste heat is transformed into other type of energy in the process of waste heat recovery. Therefore, heat pump, heat exchanger, heat pipe, boiler and refrigeration cycle are typical direct heat recovery technologies to upgrade the waste heat, while power cycles like Organic Rankine Cycle, Kalina cycle, trilateral cycle and magnetocaloric effect are typical indirect technologies to transform the waste heat into other type of energy like electric and mechanical power [32]. As shown is Fig. 1, before being delivered to the end users, the industrial waste heat will experience collection, integration or configuration depending on the waste heat process mode and then enter into suitable waste heat recovery equipment.

\subsubsection{Heat recovery by heat pump}

The thermodynamic principle of the heat pump is quite simple. It transfers low-temperature heat to high-temperature heat by consuming some high-quality energy as driving force. It is generally acknowledged that air, surface and underground water, geothermal energy sources, and other renewable energy are available low-temperature heat sources for heat pumps. Besides, the increasing heat contained in exhaust gases and waste water has been considered as an alternative heat source for heat pumps. According to the operating principle, heat pumps can be known as compression-resorption heat pumps, vapor compression heat pumps and trans-critical heat pumps [32]. Many researchers have focused on theoretical and practical studies of heat recovery using heat pumps. Theoretically, from the point of view of the pinch point [2], heat pumps should be placed across the pinch point to achieve the greatest general efficiency and benefits, while for maximizing the efficiency of recovery by heat pumps, it is necessary to optimize the energy network by identifying the pinch point. Practically, a successful application of heat recovery by heat pumps is the case of DH. The low-grade waste heat is normally unstable and fluctuates with the production level. These outstanding features distinguish low-grade industrial waste heat based DH system from conventional fossil-fueled system, e.g. CHP (Combined Heating and Power) plants and water boilers.

\subsubsection{Heat recovery by heat exchanger}

Heat exchangers are used to transfer heat between the hot fluid and cold fluid in order to meet the technical requirements of industrial processes and production. According to the operational mode of the heat transfer medium, heat exchangers can be classified as recuperative perative heat exchangers and regenerative heat exchangers. Besides, the recuperative heat exchangers include dividing-wall heat exchangers and hybrid heat exchangers. The characteristic of dividing-wall heat exchangers is that hot fluid and cold fluid are separated by 
solid wall without mixing, which is most commonly used in practical applications. Hybrid heat exchangers rely on direct heat transfer between cold and hot fluids in order to avoid the progressive clogging caused by the dividing wall. As for regenerative heat exchangers, heatconducting porous mass plays an important role in storing the thermal energy, with the advantage that it can be used in a higher temperature environment. Specifically when the operational temperature is higher than $1300 \mathrm{C}$, regenerative heat exchangers may be the only choice compared to recuperative heat exchangers [33].

In the waste heat recovery system, the heat exchanger is a very important piece of equipment. To recover low-temperature waste heat, recuperative heat exchangers showed their obvious advantages in heat exchange efficiency. In experimental conditions [34], the heat exchange efficiency reached $83.56 \%$ by combining a plate heat exchanger with a thermoelectric generator. Compared to traditional plate heat exchange, the new design involved filling open-cell metal foams in the flow channel which greatly improved the performance of heat transfer evaluated by indicators of heat exchange efficiency and pumping power. Besides, the influence of cold-water flow rate and heated air inlet temperature were analyzed to improve the performance of the heat exchanger.

\subsubsection{Heat recovery by heat pipe}

The heat pipe is an active and effective heat transfer device with simple configuration, fine compactness and without power requirements or movable mechanical parts. Compared to typical heat exchangers, as a device of recovering waste heat, heat pipe can transfer a quantity of waste heat over a long distance by virtue of its high thermal conductivity and environmental adaptability.

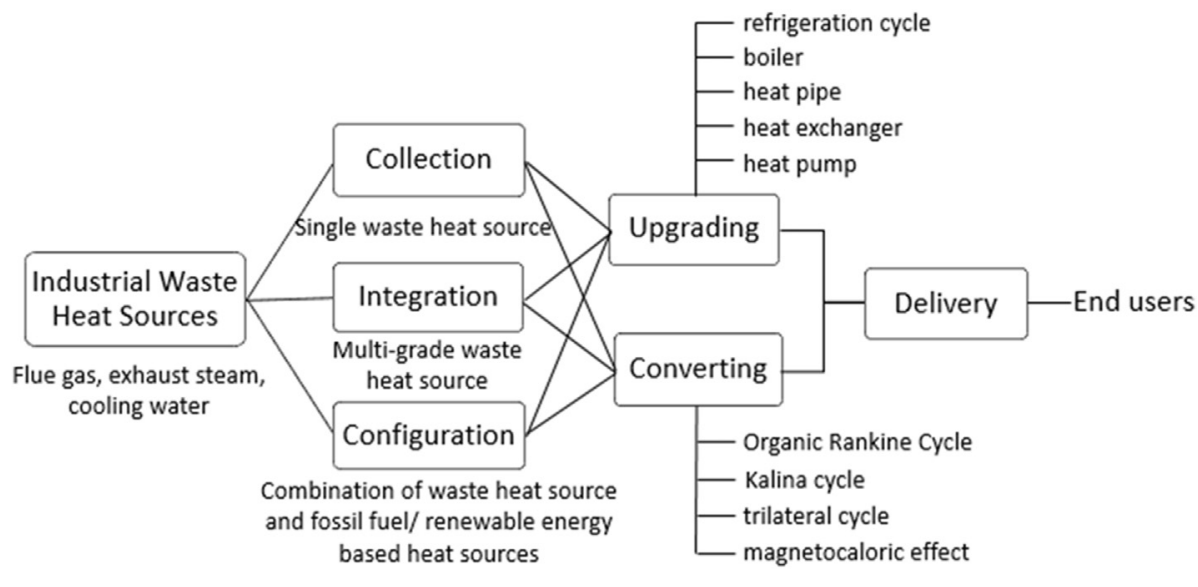

Fig. 1. The diagram of industrial waste heat recovery

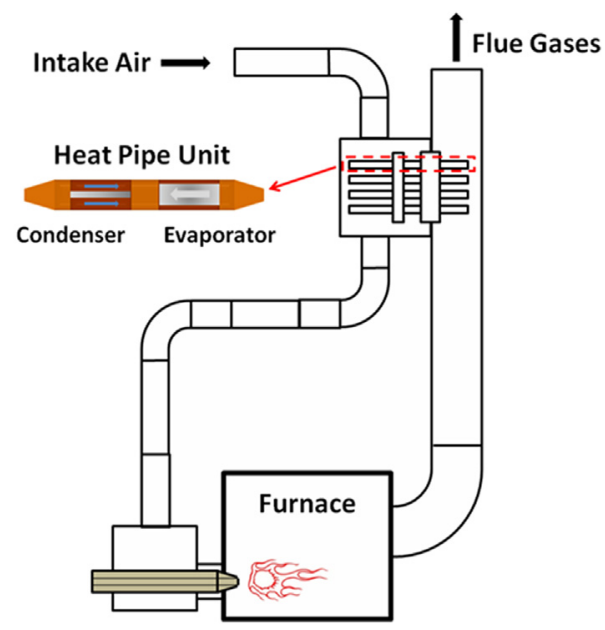

Fig. 2. Waste heat recovery using heat pipes [39].

As shown in Fig, a typical application of waste heat recovery from combustion gases uses heat pipes. The end of the heat pipe inserted into the hot waste gas is regarded as the evaporator to recover the waste heat from the flue gas. The heat-carrying medium in the pipe turns from liquid into vapor flowing to the condenser end. The condenser end is embedded into the cold/inlet air and preheats the intake air. The cooled vapor condenses and returns to the evaporator by capillary action. Apart from the evaporator and the condenser, an adiabatic section is also a necessary part in the middle of the heat pipe. It maintains a temperature difference between the evaporator end and the condenser end. The performance of heat pipes mainly depends on the heat transfer rate of the heat pipe which can be improved by broadening the heat pipe and arranging heat pipes inline [38]. Although the increased temperature of hot/waste gas contributes to the increased heat transfer rate, it is not beneficial because the higher temperature of waste gas also means more heat loss from the combustion process in the furnace. By taking full advantage of heat pipes, about $20 \%$ of fuel consumption could be saved in the furnace [39]. 
In [35], an overview was made of both traditional and modern heat pipes which can be implemented as thermal connections and highly effective heat exchangers in different systems to transfer waste heat. The heat pipe was regarded as the main component of the heat recovery system for improving energy efficiency of the whole system. Besides, in the studies of the same cooperating research teams from Australia and Malaysia [36,37], it was found that the heat pipes could be combined with a thermoelectric system for generating the power using the waste heat. A new concept of a passive heat transfer system was introduced in their research. It was composed of a thermoelectric generator (TEG) with heat pipes to heat up one side of the TEG by transferring the heat from the lower duct to the upper duct resulting in cooling the other side. A theoretical model was firstly described to provide a good start for understanding the performance of the new system laying the foundation for more detailed experimental analysis. In this system, the energy performance was greatly in fluenced by the ratio of mass flow rate from the upper duct to the lower duct [36]. Besides, the increase of air face velocity in the cold duct could improve the effectiveness of the heat pipes by recovering more free energy from the industrial waste heat [37].

\subsubsection{Heat recovery by boiler}

The temperature of the waste heat from a traditional natural gas boiler is 120 to $250 \mathrm{C}$, which can be the heat source for a heat recovery system. However, owing to the energy structural characteristics of the boiler, it is beneficial and practical to recycle the waste heat of boilers within the boiler system. Consequently, a condensing boiler was designed and used to recover the latent heat from flue gases in order to achieve higher efficiencies and less emission than the traditional boiler. Moreover, based on the principle of the existing condensing boiler, some improvements were made to optimize and enhance the performance of the condensing boiler to propose a new condensing boiler schematic $[26,27,40]$. A low temperature economizer is commonly adopted in improved boiler systems to pre-heat boiler feed water and combustion air by substituting the regenerative heater to save the extraction steam [41]. A new waste heat recovery condensing boiler was proposed in [40] where the interesting schematic diagrams of both traditional and new boiler were shown. The air ratio and exhaust gas temperature influences the efficiency of boilers. Analysis based on this fact demonstrated that high performance can generally be achieved when the boiling system is operated with a combustion chamber air inflow ratio approaching 1.0 and the outflow of low-temperature exhaust gas near 50 to $60 \mathrm{C}$. The corrosion by flue gas from the boiler of the heat recovery component/equipment is a key issue for recovering low temperature flue gases. It restricts the potential of waste heat recovery at temperatures lower than $90 \mathrm{C}$ in the common boiler applications. So, the condensed water temperature should be lower than the flue gas temperature in the condensing boiler. However, if acid-corrosion resistant materials or more reasonable heat exchange modes are feasible in the waste heat recovery boiler system, greater benefits will be acquired by lower temperature waste heat recovery.

\subsubsection{Heat recovery by refrigeration cycle}

The use of waste heat in refrigeration cycles is possible for making good use of low-grade industrial waste heat. Generally, vapor compression refrigeration, absorption refrigeration and thermoelectric refrigeration are the three main refrigeration cycles, however, the absorption refrigeration cycle is the most readily available cycle for low-temperature waste heat recovery in industry. A comprehensive review was made in 2001 [42] to summarize the various absorption refrigeration technologies in general terms and to illustrate heat recovery between absorber and generator known as GAX (Generator Absorber Heat Exchanger) in detail. It was studied using pinch analysis to maximize the potential of internal heat recovery, but waste heat recovery to activate generator operation was not mentioned in this review. Moreover, in recent decades, the shortage of primary energy and the development of industrialization have pushed ahead the use of industrial waste heat as the driving force of refrigeration cycles not limited to the steam from a boiler. So, it is meaningful to consider the application of heat recovery in refrigeration cycles. It has been noted that a high temperature is required to drive the operation of refrigeration cycles in industrial waste heat applications. Operation of the LiBr-water system requires high temperature heat source such as $85 \mathrm{C}$ or higher for activating single effect system and $150 \mathrm{C}$ for double-effect system [43]. As for low-temperature heat source, it is necessary to be upgraded to higher level for satisfying the driving demand. If a high-temperature heat source is not available, a mechanically driven heat pump can be added to the refrigeration cycle.

More new refrigeration systems were suggested based on the absorption refrigeration cycles. To satisfy energy requirements for lowtemperature cooling, the heat-driven absorption-compression refrigeration system showed more obvious advantage than the traditional absorption system because it is more economical and energy-efficient for low-temperature cooling by the combination of absorption and compression cycles [44]. In [24], a new hybrid refrigeration system was proposed to utilize the flue gases in cascade for generating the refrigerant vapor. Compared to the traditional refrigeration cycles, the proposed one has its advantages in terms of rational strategy of heat source usage and the cascaded use of the mixed working medium vapor. The combination of power and ejector-refrigeration is also an effective way of achieving cooling by recovering the low temperature heat. When more heat was transferred from the power cycle to the ejector cycle, the cooling efficiency and total energy utilization rate of the system was improved. Increasing the heat source temperature will improve the thermal efficiency and lower the total thermal conductance.

Besides, heat recovery technologies combined with adsorption were explored in industrial applications with the advantage of employing Low-grade (60 to $150 \mathrm{C}$ ) heat and the disadvantage of low efficiency and large system size [25]. An adsorption refrigeration system is made up of three main components: adsorbents container, condenser and evaporator. Under constant pressure, the temperature influences the refrigerant concentration on the adsorbent, so the operating principle of the system is that varying the temperature of the mixture could achieve the process of adsorption and desorption [45].

\subsubsection{Heat recovery by power cycle}

In practice, it is feasible to recover waste heat for power generation in industries, which can be used directly on-site in production or transferred to other places for residential users. Many studies focusing on waste heat based power generation have been carried out in different regions case by case [23,28,29]. The potential power cycles using low temperature engines for converting the low temperature waste heat into electricity mainly include: Organic Rankine cycle (ORC), Kalina cycle and Trilateral cycle (TLC). Normally, the benefit of power cycles is lower than that of heat pump cycles when the waste heat is at about $60 \mathrm{C}$, but this is not always true for higher waste heat temperatures: TLC engines could compete with heat pumps when the available waste heat is around $100 \mathrm{C}$ and the temperature of waste heat for both ORC and Kalina cycle has to be $130 \mathrm{C}$ or higher to compete with heat pumps [32]. The principle and components of power cycles were described in [46] in terms of ORC, KCS11 (Kalina cycle system 11 for power generation with low-temperature waste heat) and TLC cycles. As shown in Fig. 3 a), the basic ORC cycle is composed of an evaporator/heat recovery boiler, a turbine, a condenser and a working fluid pump. The working fluid absorbs the waste heat by heat change in the evaporator. In Fig. $3 \mathrm{~b}$ ), for all the Kalina cycles, the working fluid is an ammonia-water mixture, the advantage of which is to have different boiling and condensing temperatures, resulting in lower exergy destruction. In Fig. 3 c), the TLC cycle consists of a pump, a heater, a two-phase expander and a 
condenser. Compared to the other two cycles, the characteristic of TLC cycle is that it is able to match the expected temperature profile on the source and sink sides of the cycle.

The practice of using power cycles for recovering industrial waste heat of medium to high temperature has made great progress in recent years $[29,47]$. However, for recovering the waste heat lower than $200 \quad$ C, several key issues should be addressed to ensure that the power cycles operate efficiently. Many studies have focused on the performance of the working fluid in operating the ORC cycle, which plays a significant role in the successful operation of ORC cycles [48]. Besides, it is necessary to improve the evaporator/heater efficiency for absorbing the industrial waste heat effectively. Additionally, lack of standardization of the actual application in the design and operation of power cycles with low temperature waste heat makes it difficult to assess the technical feasibility and economic viability of power cycles. In fact, waste heat recovery by power cycles is capital-intensive and less effective. When the temperature of waste heat is between $85 \quad \mathrm{C}$ and $116 \mathrm{C}$, the net conversion factor varies from $6.62 \%$ to $7.57 \%$, while with the waste heat higher than $116 \quad \mathrm{C}$, the net conversion factor may reach $10 \%$ but in theory less than $20 \%$ [49]. Therefore, it was concluded that only when the plan of employing the power cycles based on industrial waste heat was considered in depth and when no other technologies are available to recover the waste heat, power cycles could be adopted [50].

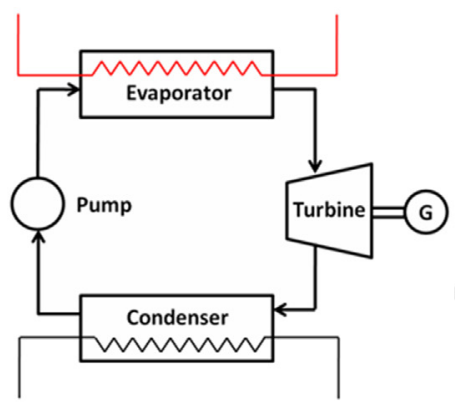

(a) ORC

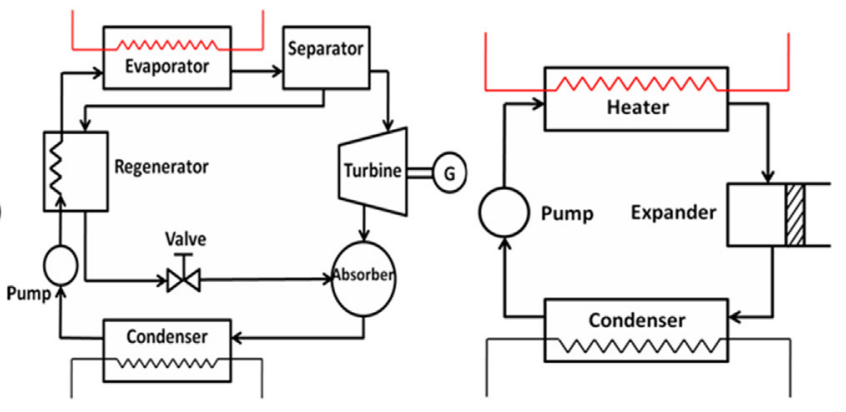

(c) TLC

Fig. 3. Schematic diagram for basic power cycles.

\subsubsection{Heat storage in industrial waste heat recovery}

Stable and sufficient waste heat sources are important to promote the development of technologies for recovering more waste heat. Due to the availability and stability characteristics of industrial waste heat, satisfying energy requirements at the peak time of the system is problematic [52]. The main function of heat storage, indirect heat recovery technology for collecting waste heat, is to confer operating flexibility on the waste heat recovery system, which takes waste heat usage out of the time-dependent process streams. Besides, for projects with long-distances between the industrial waste heat source and the heat users, M-TES (Mobile Thermal Energy Storage) was proposed to transport the heat over large distances [51]. Therefore, heat storage could make the waste heat recovery system become time independent by adjusting peak demands of the system and distance independent by improving the waste heat transportation. In [20], two modes of heat storage were discussed: long-term heat storage and short-term heat storage. Long-term storage is a simple and natural way of heat storage, which is to conserve the waste heat in rock at temperatures above $50 \quad \mathrm{C}$ during the summer and extract it from the rock in winter. Shortterm heat storage on the other hand is relatively common and has become a reliable way to reduce the fluctuations of industrial waste heat. In [53], waste steam from an incineration plant was used to charge the mobile sorption heat storage with $130 \quad \mathrm{C}$ hot air to operate an industrial drying process, which resulted in reducing the primary energy costs by $73 \mathrm{~V} / \mathrm{MWh}$ and saving operational time. Pursuing this idea, solutions associating renewable energy sources and resources including multiple thermal wastes at various temperature levels were considered and put into application to provide flexible energy productions [54e56]. These procedures make it possible to extend the prospects for the energy revalorization of heat rejections.

Therefore, heat storage can be used not only for collecting the heat from energy sources, but also for integrating multi-grade heat sources as well as for peak shaving of the system [20]. In order to improve the efficiency of the heat recovery system, traditional and variable temperature storage (VTS) systems were compared and analyzed, showing $37 \%$ more heat recovered with VTS system based on the same minimum temperature approach [54].

\section{Heat recovery opportunities in industry}

\subsection{Impacts of industrialization on energy consumption and $\mathrm{CO}_{2}$ emission}

In the process of industrialization, energy consumption is closely related to economic growth. In the early stages and medium-term of industrialization, energy consumption in general experienced a steadily upward trend. When economic development entered the period of post-industrialization, a significant change occurred to the economic growth as energy consumption began to decline. Similarly, this kind of inverted U-shaped nonlinear relationship existed in the link between industrialization and $\mathrm{CO} \quad 2$ emissions according to empirical findings in $[57,58]$. Hence, in order to reduce the influence of industrialization upon the environment, many researchers focused on the relationships between industrialization, energy consumption and $\mathrm{CO}_{2}$ emissions. In [59], a literature review was made in terms of impacts of industrialization/urbanization on energy consumption and $\mathrm{CO}_{2}$ emission, respectively. As for energy consumption, the research was reviewed from cross-country, national and city level context. There was no consistency for concluding the impacts of industrialization on energy consumption due to the complicated industrialization process and policies. For $\mathrm{CO}_{2}$ emission, representative literatures mainly focusing on industrialization development since the 1970 s were listed for helping to understand the impact of industrialization on $\mathrm{CO}_{2}$ emissions. Besides, it was pointed out that the developmental level influences the energy consumption/CO 2 by dividing 73 countries into four groups according to GDP per capita. Therefore, the developmental level of industrialization is an important factor for energy consumption, $\mathrm{CO}_{2}$ emission and economic growth. 
Industrial heat recovery requires technological and financial investments with economic and environmental benefits, which experienced varying degrees of development in different countries. In this article, the heat recovery opportunities and current technologies of both the developed countries and developing countries were considered according to published papers and research and the applicable technologies and policies were recommended internationally, especially for assisting developing countries to achieve industrialization in an ef ficient and environmental-friendly way.

\subsection{Heat recovery opportunities in the developed countries}

The heat recovery opportunities are not only related to the feasibility of technologies but also concerned by the process of industrialization which influences the availability of waste heat sources and the necessity of heat recovery. Most developed countries have experienced the process of industrialization and deindustrialization. In recent years, by reconsidering the importance of manufacturing in economic growth for creating employment opportunities and national income, the strategy of reindustrialization has been put forward by USA, Germany, France, Japan and so on for adjusting the industrial structure. Industrial energy consumption accounts for almost $20 \%$ of the total energy consumption [60], so there is a great potential for recovering waste heat especially the low-temperature waste heat under $200 \mathrm{C}$ in developed countries.

In the process of industrial development, most developed countries have adopted heat recovery technologies for improving energy efficiency. The UK has been practicing industrial heat recovery for more than four decades. Many articles have been published with the aim of sharing the successful engineering practices in terms of the performance of different waste heat recovery technologies as well as the difficulties and problems encountered. In recent decades, among the developed countries, UK is one of the countries with the most papers published pertaining to industrial waste heat recovery in terms of identifying waste heat sources and opportunities, optimizing the configuration of heat supply and heat demand and choosing suitable heat recovery technologies and systems [60e63]. Compared to other countries, the energy data of industrial waste heat have been recorded by the improved supervisory system, which is important to know the status and contribution of industrial heat recovery technologies and perform quantitative analysis [60,61]. Besides, the energy audit is a prevailing way of accessing energy consumption data, but the adoption and investment of energy efficiency technologies will be influenced by the quality of the energy audit [64]. So, efficient energy management and data collection mode will make the advantages and benefits of waste heat recovery more visible and convincing for others. However, in Germany, the rules of data protection are so strict for the sake of trade secrets that most industrial waste heat data are not available directly from industries, so reliable estimation methods could be an effective alternative for calculating the amount of available waste heat indirectly [65]. For EU 27, the new heat roadmap was proposed by considering the recovery of surplus heat from power plants, industries, and waste incineration and re-injecting it into a network of $\mathrm{DH}$, which will increase the proportion of reused waste heat in the total amount of energy consumption in Europe [2].

Industrial waste heat recovery can be more practical in the most developed countries with the help of advanced technologies, centralized industries and strict limitation of $\mathrm{CO}_{2}$ emission. Certain measures have been tested in real practice for years, with constant modification according to the demand of practical activities. This sets a good example for other countries. However, it is also a fact that the total amount of energy consumption in developed countries is high which makes the contribution of industrial waste heat for saving primary energy rare especially in the case that the industrial waste heat is considered for the supply of heating or hot water to residential users [65]. Generally, the traditional energy system needs to be supplemented to fulfill the energy demand. Therefore, apart from the energy and economic benefits, the environmental issues should be considered completely as it has played an increasingly important role in global development [66].

\subsection{Heat recovery opportunities in the developing countries}

Most developing countries are in the process of industrialization and urbanization facing the shock of globalization, so opportunities and challenges coexist for the promotion of sustainable development. The development of heat recovery technologies, as one of the sustainable technologies, suffers from technological, financial, and institutional barriers in developing countries [67]. Specifically, in the context of global competition, it is difficult for developing countries to obtain the advanced technologies and hence gain access to the international technology market and it is easy to suffer limited ability and experience of choosing the optimal technologies. Besides, the lack of budget for both fundamental research and imported technologies and equipment is the delicate situation of heat recovery technology in developing countries. Moreover, the institutional establishment is the cornerstone for ensuring the stability and sustainability of heat recovery technologies in terms of policies, financial allocation, information exchange, supervision systems and so on, and in developing countries individual institutions can easily remain out of touch.

However, the desire for rapid economic development in a sustainable way by assimilating the experience gained during the industrialization of developed countries based on the environmental requirements of reducing greenhouse gas emission provides a great potential for installing heat recovery technologies during industrialization of developing countries. Unlike in the 20th century, when the efforts of industrialization projects in developing countries were rare and tentative, more recently, structural improvements in the industry at the national level have been beneficial for industrial expansion [68]. Accompanied by the tendency towards globalization, the market of developing industries and infrastructures will attract more attention from developed countries to boost industrialization. It is actually a typical winewin situation called exchanging the market for technologies and investment in the process of industrialization. China is the largest economic entity of the developing countries, and accounts for $30 \%$ of global economic increment. Keeping economic growth and promoting new-style industrialization are still the main targets of the Chinese national plan of "Thirteenth Five-Year Plan", while the promise to the whole world of fulfilling the target of decreased $\mathrm{CO}_{2}$ emission should be achieved in a scientific and harmonious way, which provides opportunities of green development by recovering industrial waste heat.

\section{Case studies in Asian countries}

In [69], four cases from France, Germany, Spain and Canada were compared with their sub-regions respectively in terms of energy consumed by the industry, industrial waste heat potential and its share in industrial energy consumption. The common characteristic of these countries and sub-regions is that industrial energy consumption plays a pivotal role in total energy consumption. All are industrialized countries and all the sub-regions are industry-centered zones in their countries. However, the waste heat potential varies from country to country and from region to region. It is difficult to come to any general conclusions because the data from the literature use different methods of analysis and sources of information whose reliability is not always totally convincing and in addition, the industrial processes are 
so complicated and unstable that no clear profile of industrial waste heat can be given. Even so, it is meaningful to give a general outline of waste heat potential for developing the waste heat recovery technologies in different countries based on case studies. In this article, attention has been paid to Asian countries, most of which are in the process of industrialization. Case studies of waste heat potential and waste heat recovery engineering applications in China, Malaysia, and Singapore, which were not mentioned in [69] are reviewed below.

\subsection{Case 1: China and its District Heating}

In China, existing industries contributed to the waste of industrial energy consumption by as much as $50 \%$. Based on the consideration of economic and environmental condition, DH has only been performed in northern China since 1980s supported by the government. Recently, some DH projects were performed at the level of industrial parks and residential areas according to local requirements beyond northern China. As a result, the comfort of the indoor thermal environment has been improved, but it also brought about several serious problems such as high energy consumption and high environmental pollution.

The retrofit of $\mathrm{DH}$ for improving energy efficiency has been considered, planed and performed for decades by introducing applicable technologies. While for new ventures, many new technologies have been fully applied to develop DH in the form of demonstration projects with the financial support from government, aiming to reduce the consumption of primary energy and relieve the environmental burden. In fact, more and more demonstration projects have been put into practice, and have proved to be an effective way of testing the feasibility and adaptability of new technologies.

Collecting industrial waste heat for $\mathrm{DH}$ shows great potential in northern China [19]. As shown in Table 1, while about $34 \%$ of industrial low-temperature waste heat could be used as the heat source of $\mathrm{DH}$, theoretically, all $\mathrm{DH}$ could operate without consuming primary energy when calculations are based on the energy data of 2009. So far, concerning the low-temperature industrial waste heat for the $\mathrm{DH}$, only two projects have been found in published articles (see Table 2).

Table 1

Typical applications of waste heat recovery in the recent literature.

\begin{tabular}{|c|c|c|c|}
\hline $\begin{array}{l}\text { Waste heat } \\
\text { source }\end{array}$ & $\begin{array}{l}\text { Waste heat } \\
\text { temperature }\end{array}$ & Application & Illustration \\
\hline \multirow[t]{7}{*}{ Flue gas } & $250 \mathrm{C}$ at the exit & Heat recovery steam generator in waste incineration & Heat exchangers as key equipment in the process $[21,22]$ \\
\hline & $350 \mathrm{C}$ & Refrigerant vapor output in industries with flue gases & Superheated $\mathrm{NH}_{3} \mathrm{eH}_{2} \mathrm{O}$ vapor was used in cascade [24] \\
\hline & $164 \mathrm{C}$ & $\begin{array}{l}\text { Meet the freezer requirement from } 25 \text { to } 18 \mathrm{C} \\
\text { in crisps manufacturing plant }\end{array}$ & $\begin{array}{l}\text { Two refrigeration system were compared in terms of } \\
\text { thermodynamic performance [25] }\end{array}$ \\
\hline & $90 \mathrm{e} 131 \mathrm{C}$ & $\begin{array}{l}\text { Replace part of the extraction steam in } \\
\text { heating the condensed water to increase work } \\
\text { output in coal-fired power plant }\end{array}$ & $\begin{array}{l}\text { Based on the location of condensed water, four typical } \\
\text { cases of exhaust utilization have been implemented [26] }\end{array}$ \\
\hline & $122.8 \mathrm{C}$ & $\begin{array}{l}\text { Low-pressure economizer was used for heating } \\
\text { feed water in coal-fired power plant with wet stack }\end{array}$ & $\begin{array}{l}\text { Acid corrosion was a key consideration when } \\
\text { selecting the optimal scheme among three cases [27] }\end{array}$ \\
\hline & $\begin{array}{l}200 \mathrm{e} 300 \mathrm{C}(165 \mathrm{C} \\
\text { to ORC module) }\end{array}$ & $\begin{array}{l}\text { ORC modules for power generation } \\
\text { in ceramic industry }\end{array}$ & $\begin{array}{l}\text { The characteristic is to verify the performance of } \\
\text { ORC operating in actual industrial conditions } \\
\text { compared to laboratory data [28] }\end{array}$ \\
\hline & $416 \mathrm{C}$ & $\begin{array}{l}\text { ORC model for power generation based on } \\
\text { field data in a gas treatment plant }\end{array}$ & $\begin{array}{l}\text { By setting and comparing the basic model and } \\
\text { regenerative model for modifying the ORC } \\
\text { model in order to decide the most suitable working } \\
\text { fluid and the most effective working condition [29] }\end{array}$ \\
\hline Exhausted steam & $37 \mathrm{C}$ & $\mathrm{DH}$ in cogeneration & $\begin{array}{l}\text { Due to heat recovery units, the heat capacity } \\
\text { increased to } 400 \mathrm{MW} \text {, satisfying the heat } \\
\text { requirement of } 6.4 \text { million } \mathrm{m}^{2} \text { [30] }\end{array}$ \\
\hline \multirow[t]{2}{*}{ Cooling water } & $8 \mathrm{e} 20 \mathrm{C}$ & $\begin{array}{l}\text { Heat pumps for heating buildings based on } \\
\text { waste from wastewater treatment }\end{array}$ & $\begin{array}{l}\text { Wastewater shows high and stable temperature } \\
\text { compared to the ambient air [31] }\end{array}$ \\
\hline & $55 \mathrm{e} 85 \mathrm{C}$ & Waste heat for activating adsorption desalination & $\begin{array}{l}\text { Heat recovery between the condenser and the } \\
\text { evaporator was also considered [23] }\end{array}$ \\
\hline Multi-sources & $20 \mathrm{e} 90$ & DH based on waste from copper smelter & $\begin{array}{l}\text { Waste heat is the basic heat source for } \mathrm{DH} \text { while the } \\
\text { fossil-fuel heat is used for the purpose of the peak shave [20] }\end{array}$ \\
\hline
\end{tabular}

Table 2

Energy consumed by the industry and District Heating of Northern China.

\begin{tabular}{lll}
\hline Northern China (2009) & Industries & District Heating \\
\hline Energy consumption & 42.85 billion GJ & 2.6 billion GJ $^{\mathrm{b}}$ \\
Low-temperature & 7.6 billion $\mathrm{GJ}^{\mathrm{b}}$ & $\mathrm{e}$ \\
Waste heat potential & $17.74 \%$ & $34 \%$ of industrial waste heat recovery \\
Share & & 3 \\
\hline
\end{tabular}

a Data source: China energy conservation development report 2011

b Data source: [70].

One is located in the Chifeng City, northern China. The research team has published two articles in international journals about this project. The first focused on heat collection from different waste heat sources of both a copper smelter and a cement plant, which involved and solved the issue of the integration of different types of equipment for collecting different grades of the waste heat in cascade [70]. The second reported the critical issues in the process of recovering waste heat for $\mathrm{DH}$, including waste heat sources collection and integration, which has also been studied in detail in ref. [70], involving long distance delivery and peak shaving [20]. These issues were solved successfully in the case study for providing the reference of the same project with similar. Consequently, $390,000 \mathrm{GJ}$ of waste heat was recovered resulting the reduction of 35,000 t of $\mathrm{CO}_{2}$ emission.

The other case study was located in the Datong City, northern China. The fundamental system of combining the cogeneration and absorption (Co-ah system) was introduced by establishing waste heat recovery units and absorption heat exchanger units for recovering exhaust steam in order to satisfy the heating requirement of $\mathrm{DH}$. The expected results were obtained based on experimental data that the total heating power could reach $138 \mathrm{MW}$ from waste steam, which was capable of providing sufficient heat for added residential heating area. 
One is located in the Chifeng City, northern China. The research team has published two articles in international journals about this project. The first focused on heat collection from different waste heat sources of both a copper smelter and a cement plant, which involved and solved the issue of the integration of different types of equipment for collecting different grades of the waste heat in cascade [70]. The second reported the critical issues in the process of recovering waste heat for $\mathrm{DH}$, including waste heat sources collection and integration, which has also been studied in detail in ref. [70], involving long distance delivery and peak shaving [20]. These issues were solved successfully in the case study for providing the reference of the same project with similar. Consequently, 390,000 GJ of waste heat was recovered resulting the reduction of 35,000 t of $\mathrm{CO}_{2}$ emission.

The other case study was located in the Datong City, northern China. The fundamental system of combining the cogeneration and absorption (Co-ah system) was introduced by establishing waste heat recovery units and absorption heat exchanger units for recovering exhaust steam in order to satisfy the heating requirement of $\mathrm{DH}$. The expected results were obtained based on experimental data that the total heating power could reach $138 \mathrm{MW}$ from waste steam, which was capable of providing sufficient heat for added residential heating area.

Besides, our research team studied a demonstration project of cloud computing centers with CCHP energy system considering the waste heat recovery, located in Chongqing, China [71e74]. In our study case, the waste heat sources include low temperature exhaust steam from steam turbine, low-temperature heat produced by server heat dissipation from data centers and cooling water from a power plant. Low temperature exhausted steam was used to provide cooling for data centers using $\mathrm{LiBr}$ absorption refrigeration, and both low temperature heat from data centers and cooling water were considered as the heat sources of DH to provide the heating for residential buildings. As shown in Fids, data center waste heat is captured through a plate heat exchanger at the place next to the evaporator.

\subsection{Case 2: Malaysia and its oil palm industries}

Malaysia is a country with a large amount of energy sources, being famous for oil and natural gas. Even the Malaysian government has made efforts to promote the development of renewable energy, acceptance of renewable energy technologies is not yet maximal and the market share of renewable energy is too low to be commercially available [75]. Palm oil is the fundamental backbone industry of Malaysian economic growth. As the palm oil industries expand, the palm oil biomass waste has been paid more attention as a source of renewable energy. From the point of view of energy recovery, palm oil biomass waste could be put into combustion directly to produce useful energy as an alternative to primary energy. To produce 1 ton palm oil needs $75 \mathrm{e} 1000 \mathrm{kWh}$ electricity and 2.5 tons steam. At the same time, 4 tons of

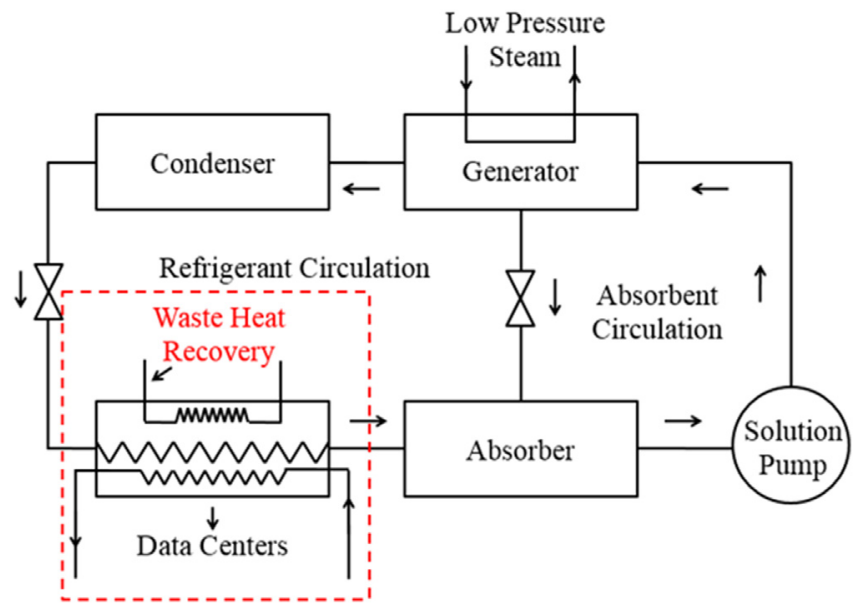

Fig. 4. Schematic of absorption refrigeration with waste heat recovery [71].

dry biomass is produced as by-product which should be reused or will result in global warming. While to obtain $75 \mathrm{e} 1000 \mathrm{kWh}$ electricity and 2.5 tons steam, only $0.3 \mathrm{e} 0.4$ tons biogas is required $[76,77]$. However, the electricity produced by palm oil industry waste only reached about $1 \mathrm{e} 1.5$ billion $\mathrm{kWh}$, which was equal to $2 \%$ of 2003 power generation in Malaysia. Benefitting from the policies of developing renewable energy and the application of promising technologies, the ratio of waste-activated power to fossil fuel activated power is improving but still limited as shown in [78] that palm oil industry waste did not show the overwhelming advantage compared to other renewable energy sources.

\subsection{Case 3: Singapore and its industrial parks}

Singapore is one of the developed countries in Asia with a successful experience of industrialization, especially famous for the construction and operation of industrial parks. In 1961, the Jurong Industrial Estate/Park was established for accelerating the process of industrialization as well as developing the national economy, and has proved to be a great success. Currently, there are more than 30 industrial parks in Singapore, amounting to $11.2 \%$ of national territorial area. However, the industrial sector consumed about $51.6 \%$ of the total energy in 2012 according to the IEA statistics [79], increasing to 65\% in 2013 according to Singapore Energy Statistics [80]. To cope with the shortage of energy and land resources, the ecosystem concept has been applied to designing the industrial parks since 2004 [81] and evolved to become the idea of Eco-industrial Park. One of the most important characteristics of the eco-industrial park is to reuse flows of materials and energy between different industrial processes.

shown in Table 3, the majority of electricity, natural gas and oil were attributed to the industrial-related sector. As for the power generation industry, $97 \%$ of electricity was generated by Combined Cycle Turbines, Co-Generation Plants and/or Tri-Generation Plants, while the remainder was generated by steam turbines, open cycle gas turbines and waste-to-energy plants. Considering industrial waste heat recovery, there was no project in operation found in the previous literature. Only it was recorded NatSteel enterprise introduced a heat recovery system for reusing the heat from the steel production process in 2013, but there is no related article and even no idea about the destination of the recovered industrial waste heat. 


\subsection{Conclusions}

The importance of heat recovery in industrial zones will receive more attention with the increase of economic development and the resulting air pollution. For researchers and technicians, it is necessary to update the information on state of the art heat recovery technologies in order to improve the energy performance of industrial systems. First however, it is important to consider the adaptability of new technologies and the influence of the adoption of waste heat recovery systems in the original industrial process. For managers and investors, the economic benefits and pollutant discharges are the top priorities because the former is the motivation of investment and the latter is increasingly required by the government, aiming to fulfill the sustainable development by protecting the environment. For the government,

Table 3

Total energy consumption and industrial-related consumption in Singapore.

\begin{tabular}{lll}
\hline Energy type & Total consumption & Industrial-related consumption \\
\hline Electricity (2014) & $46 \mathrm{TWh}$ & $20 \mathrm{TWh}$ \\
Natural gas (2014) & $59,427 \mathrm{TJ}$ & $52,436 \mathrm{TJ}$ \\
Oil (2013) & $8136 \mathrm{ktoe}$ & $5886 \mathrm{ktoe}$ \\
Total final energy consumption (2013) & $13,425 \mathrm{ktoe}$ & $8779 \mathrm{ktoe}$ \\
\hline
\end{tabular}

Data sources: Singapore energy statistics 2015 [80].

acting effectively in the process of macroscopic readjustment and control by supporting and promoting the application of practical and beneficial heat recovery technologies requires drawing from successful experience in both developed and developing countries. The aim of this article is to provide a comprehensive review of heat recovery technologies to know the current status and the market perception of technologies for the purpose of improving the technical adaptability. Also the intention is to support decision-making progress of industrial zones by specifying technical parameters of the integration of industrial process systems and heat recovery systems for newly installed plant. Moreover, many details should be considered for existing industries with a desire and the requirement for heat recovery renovation. So, it is beneficial to overview the successful applications of heat recovery technologies.

\subsection{Perspectives for industrial waste heat recovery}

Industrial waste heat recovery is essentially the exploitation of the exhaust gases and steam and cooling water that result from the inefficiencies of industrial equipment and utilities. The adoption of more efficient production technologies and advanced management modes may therefore limit the waste heat available in the future. Besides, the structural revolution of industrialization in developed countries, could considerably affect the availability of waste heat [60]. However, for most developing countries, accounting for more than a half of the world population, industrialization is still in progress, and will require a long time to achieve industrialization in an orderly way. The good case studies and engineering experiences from developed countries and well-industrialized zones of developing countries will provide examples for the developing countries to avoid taking wrong turnings on their way towards industrialization. Therefore, for a long time yet, it will remain meaningful to pay great attention to industrial heat recovery globally.

\section{Acknowledgments}

Financial support of ERASMUS MUNDUS Techno 2 project and hospitality of laboratory PHASE of UT3-PS in the framework of project "OptiMEP: Management of Energy for Patrimonial purpose", is gratefully acknowledged. Meanwhile, thanks for the support of National Science Foundation of China (No. 51478058).

\section{References}

[1] E. Efficiency, Tracking industrial energy efficiency and CO 2 emissions, Int. Energy Agency 34 (2007) 1e12.

[2] Institution of Chemical Engineers, R, A User Guide on Process Integration for the Efficient Use of Energy, 1982.

[3] Y. Geng, Z. Hengxin, Industrial park management in the Chinese environment, J.Clean. Prod. 17 (2009) $1289 \mathrm{e} 1294$.

[4] A.-M. Heikkil 自, Y. Malmen, M. Nissild, H. Kortelainen, Challenges in risk management in multi-company industrial parks, Saf. Sci. 48 (2010) 430 e435.

[5] T. Maes, G. Van Eetvelde, E. De Ras, C. Block, A. Pisman, B. Verhofstede, F. Vandendriessche, L. Vandevelde, Energy management on industrial parks in Flanders, Renew. Sustain. Energy Rev. 15 (2011) 1988e2005.

[6] Y. Qu, Y. Liu, R.R. Nayak, M. Li, Sustainable development of eco-industrial parks in China: effects of managers' environmental awareness on the relationships between practice and performance, J.Clean. Prod. 87 (2015) 328e338.

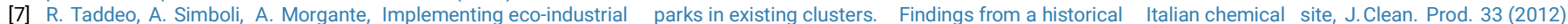
$22 \mathrm{e} 29$.

[8] F. Yu, F. Han, Z. Cui, Evolution of industrial symbiosis in an eco-industrial park in China, J.Clean. Prod. 87 (2015) 339 e347.

[9] I. Mannino, E. Ninka, M. Turvani, M. Chertow, The decline of eco-industrial development in Porto Marghera, Italy, J.Clean. Prod. 100 (2015) 286 e296.

[10] M. Aman, K. Solangi, M. Hossain, A. Badarudin, G. Jasmon, H. Mokhlis, A. Bakar, S. Kazi, A review of safety, health and environmental (SHE) issues of solar energy system, Renew. Sustain. Energy Rev. 41 (2015) 1190e1204.

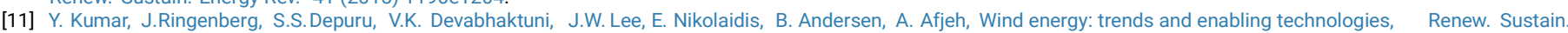
Energy Rev. 53 (2016) $209 \mathrm{e} 224$.

[12] S. Upadhyay, M. Sharma, A review on configurations, control and sizing methodologies of hybrid energy systems, Renew. Sustain. Energy Rev. 38 (2014) 47e63.

[13] K.S. Krishna, K.S. Kumar, A review on hybrid renewable energy systems, Renew. Sustain. Energy Rev. 52 (2015) 907 e916.

[14] V.G. Gude, Energy storage for desalination processes powered by renewable energy and waste heat sources, Appl. Energy 137 (2015) 877 , 898.

[15] Z.-H. Liu, H.-Y. Guan, G.-S. Wang, Performance optimization study on an integrated solar desalination system with multi-stage evaporation/heat recovery processes, Energy 76 (2014) 1001e1010.

[16] M. Bendig, F. Marechal, D. Favrat, Defining "waste heat” for industrial processes, Appl. Therm. Eng. 61 (2013) $134 \mathrm{e} 142$.

[17] S. Brückner, S. Liu, L. Mir o, M. Radspieler, L.F. Cabeza, E. L\&ivemann, Industrial waste heat recovery technologies: an economic analysis of heat transformation technologies, Appl. Energy 151 (2015) 157 e167.

[18] M.Z. Stijepovic, P. Linke, Optimal waste heat recovery and reuse in industrial zones, Energy 36 (2011) $4019 \mathrm{e} 4031$.

[19] National Development and Reform Commission, Ministry of Housing and Urban-rural. Plans to implement projects on surplus heat recovery for residential heating. http://www.sdpc.gov.cn/zcfb/zcfbtz/201511/t20151104_757519.html.

[20] H. Fang, J.Xia, Y. Jiang, Key issues and solutions in a district heating system using low-grade industrial waste heat, Energy 86 (2015) 589 e602.

[21] M. Pavlas, M. Tous, P. Klimek, L. Bebar, Waste incineration with production of clean and reliable energy, Clean Technol. Environ. Policy 13 (2011) 595 e605.

[22] B. Kilkovsky, P. Stehlik, Z. Jegla, L.L. Tovazhnyansky, O. Arsenyeva, P.O. Kapustenko, Heat exchangers for energy recovery in waste and biomass to energy technologies el. Energy recovery from flue gas, Appl. Therm. Eng. 64 (2014) $213 e 223$. 
[23] K. Thu, H. Yanagi, B.B. Saha, K.C. Ng, Performance analysis of a low-temperature waste heat-driven adsorption desalination prototype, Int. J. Heat Mass Transf. 65 (2013) $662 \mathrm{e} 669$.

[24] L. Sun, W. Han, H. Jin, Energy and exergy investigation of a hybrid refrigeration system activated by mid/low-temperature heat source, 913e923.

[25] M. Aneke, B. Agnew, C. Underwood, M. Menkiti, Thermodynamic analysis of alternative refrigeration cycles driven from waste heat in a food processing application, Int. J.Refrig. 35 (2012) 1349e1358.

[26] G. Xu, S. Huang, Y. Yang, Y. Wu, K. Zhang, C. Xu, Techno-economic analysis and optimization of the heat recovery of utility boiler flue gas, Appl. Energy $112(2013)$ $907 e 917$

[27] C. Wang, B. He, S. Sun, Y. Wu, N. Yan, L. Yan, X. Pei, Application of a low pressure economizer for waste heat recovery from the exhaust flue gas in a 600 MW power plant, Energy 48 (2012) 196e202.

[28] B. Peris, J.Navarro-Esbrí, F. Moles, A. Mota-Babiloni, Experimental study of an ORC (organic Rankine cycle) for low grade waste heat recovery in a ceramic industry, Energy 85 (2015) 534e542.

[29] M.A. Khatita, T.S. Ahmed, F.H. Ashour, I.M. Ismail, Power generation using waste heat recovery by organic Rankine cycle in oil and gas sector in Egypt: a case study, Energy 64 (2014) 462e472

[30] Y. Li, L. Fu, S. Zhang, Technology application of district heating system with Co-generation based on absorption heat exchange, Energy 90 (2015) 663e670.

[31] L.N. Alekseiko, V.V. Slesarenko, A.A. Yudakov, Combination of wastewater treatment plants and heat pumps, Pac. Sci. Rev. 16 (2014) 36 39.

[32] D. van de Bor, C.I. Ferreira, A.A. Kiss, Low grade waste heat recovery using heat pumps and power cycles, Energy 89 (2015) 864 e873.

[33] J.A.Willmott, Dynamics of Regenerative Heat Transfer, CRC Press, 2001.

[34] T. Wang, W. Luan, W. Wang, S.-T. Tu, Waste heat recovery through plate heat exchanger based thermoelectric generator system,

[35] L.L. Vasiliev, Heat pipes in modern heat exchangers, Appl. Therm. Eng. 25 (2005) 1 e19.

[36] M. Remeli, L. Kiatbodin, B. Singh, K. Verojporn, A. Date, A. Akbarzadeh, Power generation from waste heat using heat pipe and thermoelectric generator, Energy Procedia 75 (2015) 645e650.

[37] M. Remeli, K. Verojporn, B. Singh, L. Kiatbodin, A. Date, A. Akbarzadeh, Passive heat recovery system using combination of heat pipe and thermoelectric generator, Energy Procedia 75 (2015) 608e614.

[38] L. Yodrak, S. Rittidech, N. Poomsa-ad, P. Meena, Waste heat recovery by heat pipe air-preheater to energy thrift from the furnace in a hot forging process, Am. J. Appl. Sci. 7 (2010) 675e681.

[39] H. Shabgard, M.J. Allen, N. Sharifi, S.P. Benn, A. Faghri, T.L. Bergman, Heat pipe heat exchangers and heat sinks: opportunities, challenges, applications, analysis, and state of the art, Int. J. Heat Mass Transf. 89 (2015) 138e158.

[40] C.-E. Lee, B. Yu, S. Lee, An analysis of the thermodynamic efficiency for exhaust gas recirculation-condensed water recirculation-waste heat recovery condensing boilers (EGR-CWR-WHR CB), Energy 86 (2015) 267e275.

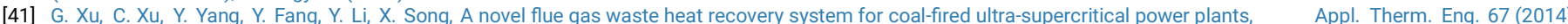
$240 \mathrm{e} 249$.

[42] P. Srikhirin, S. Aphornratana, S. Chungpaibulpatana, A review of absorption refrigeration technologies, Renew. Sustain. Energy Rev. 5 (2001) $343 e 372$.

[43] R. Wang, Z. Xia, L. Wang, Z. Lu, S. Li, T. Li, J. Wu, S. He, Heat transfer design in adsorption refrigeration systems for efficient use of low-grade thermal energy, Energy 36 (2011) 5425e5439.

[44] Y. Chen, W. Han, H. Jin, An absorptionecompression refrigeration system driven by a mid-temperature heat source for low-temperature applications, Energy 91 (2015) $215 \mathrm{e} 225$.

[45] U. Lucia, Adsorber efficiency in adsorbtion refrigeration, Renew. Sustain. Energy Rev. 20 (2013) 570 e575.

[46] M. Yari, A. Mehr, V. Zare, S. Mahmoudi, M. Rosen, Exergoeconomic comparison of TLC (trilateral Rankine cycle), ORC (organic Rankine cycle) and Kalina cycle using a low grade heat source, Energy 83 (2015) 712 e722.

[47] F. Campana, M. Bianchi, L. Branchini, A. De Pascale, A. Peretto, M. Baresi, A. Fermi, N. Rossetti, R. Vescovo, ORC waste heat recovery in European energy intensive industries: energy and GHG savings, Energy Convers. Manag. 76 (2013) 244e252.

[48] H. Jung, S. Krumdieck, T. Vranjes, Feasibility assessment of refinery waste heat-to-power conversion using an organic Rankine cycle, Energy Convers. Manag. 77 (2014) $396 \mathrm{e} 407$.

[49] V. Minea, Power generation with ORC machines using low-grade waste heat or renewable energy, Appl. Therm. Eng. 69 (2014) 143e154.

[50] H. Lu, L. Price, Q. Zhang, Capturing the invisible resource: analysis of waste heat potential in Chinese industry, Appl. Energy 161 (2016) 497 511.

[51] J.N.W. Chiu, et al., Industrial surplus heat transportation for use in district heating, Energy (2016), http://dx.doi.org/10.1016/j.energy.2016.05.003.

[52] A. Anastasovski, P. Raskovic, Z. Guzovi c, Design and analysis of heat recovery system in bioprocess plant, Energy Convers. Manag. 104 (2015) 32e43.

[53] A. Krønauer, E. Lfivemann, S. Brückner, A. Hauer, Mobile sorption heat storage in industrial waste heat recovery, Energy Procedia 73 (2015) 272e280.

[54] T.G. Walmsley, M.R. Walmsley, M.J. Atkins, J.R. Neale, Integration of industrial solar and gaseous waste heat into heat recovery loops using constant and variable temperature storage, Energy 75 (2014) 53 e67.

[55] M.J. Atkins, M.R. Walmsley, A.S. Morrison, Integration of solar thermal for improved energy efficiency in low-temperature-pinch industrial processes, Energy 35 (2010) $1867 \mathrm{e} 1873$

[56] T.G. Walmsley, M.R. Walmsley, A.H. Tarighaleslami, M.J.Atkins, J.R.Neale, Integration options for solar thermal with low temperature industrial heat recovery loops, Energy 90 (2015) 113e121.

[57] B. Xu, B. Lin, How industrialization and urbanization process impacts on CO 2 emissions in China: evidence from nonparametric additive regression models, Energy Econ. 48 (2015) 188e202.

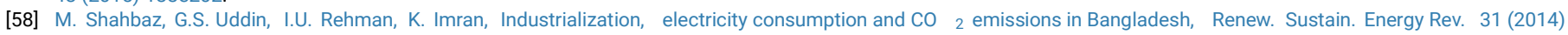
$575 \mathrm{e} 586$.

[59] K. Li, B. Lin, Impacts of urbanization and industrialization on energy consumption/CO 2 emissions: does the level of development matter? Renew. Sustain. Energy Rev. 52 (2015) $1107 \mathrm{e} 1122$.

[60] G. Hammond, J.Norman, Heat recovery opportunities in UK industry, Appl. Energy 116 (2014) 387 e397.

[61] R.C. McKenna, J.B.Norman, Spatial modelling of industrial heat loads and recovery potentials in the UK, Energy Policy 38 (2010) 5878 e5891.

[62] Y. Ammar, S. Joyce, R. Norman, Y. Wang, A.P. Roskilly, Low grade thermal energy sources and uses from the process industry in the UK, Appl. Energy 89 (2012) 3 e20.

[63] L. Sun, S. Doyle, R. Smith, Heat recovery and power targeting in utility systems, Energy 84 (2015) $196 \mathrm{e} 206$.

[64] T. Fleiter, J. Schleich, P. Ravivanpong, Adoption of energy-efficiency measures in SMEsdAn empirical analysis based on energy audit data from Germany, Energy Policy 51 (2012) $863 e 875$.

[65] S. Brückner, H. Sch fffers, I. Peters, E. L息vemann, Using industrial and commercial waste heat for residential heat supply: a case study from Hamburg, Germany, Sustain . Cities Soc. 13 (2014) 139e142.

[66] V. Jain, G. Sachdeva, S.S. Kachhwaha, Energy, exergy, economic and environmental (4E) analyses based comparative performance study and optimization of vapor compression-absorption integrated refrigeration system, Energy 91 (2015) 816e832.

[67] M. Suzuki, Identifying roles of international institutions in clean energy technology innovation and diffusion in the developing countries: matching barriers with roles of the institutions, J.Clean. Prod. 98 (2015) $229 \mathrm{e} 240$.

[68] A. Szirmai, Industrialisation as an engine of growth in developing countries, 1950e2005, Struct. Change Econ. Dyn. 23 (2012) 406e420.

[69] L. Miro, S. Brückner, L.F. Cabeza, Mapping and discussing industrial waste heat (IWH) potentials for different countries, Renew. Sustain. Energy Rev. 51 (2015) 847 e855.

[70] H. Fang, J.Xia, K. Zhu, Y. Su, Y. Jiang, Industrial waste heat utilization for low temperature district heating, Energy Policy 62 (2013) $236 \mathrm{e} 246$.

[71] F. Huang, J.Lu, J.Zheng, J.M. Baleynaud, Feasibility of heat recovery for district heating based on cloud computing industrial park, in: Proceedings of 4th International Conference on Renewable Energy Research and Applications, 2015.

[72] C. Li, Research on the Coupling Characteristics and System Optimization of District CCHP, Chongqing University, 2013 (in Chinese, PhD thesis).

[73] L. Yang, The Research about Waste Energy Utilization in "Cloud Computing" Industrial Parks, Chongqing University, 2014 (in Chinese, Master thesis).

[74] S. Zhang, Optimal Research of CCHP System in Cloud Computing Industrial Park, Chonqging University, 2014 (in Chinese, Master thesis).

[75] R. Kardooni, S.B. Yusoff, F.B. Kari, Renewable energy technology acceptance in Peninsular Malaysia, Energy Policy 88 (2016) 1 e 10.

[76] F. Sulaiman, N. Abdullah, H. Gerhauser, A. Shariff, An outlook of Malaysian energy, oil palm industry and its utilization of wastes as useful resources, Biomass Bioenergy 35 (2011) 3775e3786.

[77] S.E. Hosseini, M.A. Wahid, Utilization of biogas released from palm oil mill effluent for power generation using self-preheated reactor, (2015) $957 e 966$

[78] R. Ali, I. Daut, S. Taib, A review on existing and future energy sources for electrical power generation in Malaysia, Renew. Sustain. Energy Rev, 16 (2012) 4047 4055.

[79] K.-H. Chai, C. Baudelaire, Understanding the energy efficiency gap in Singapore: a motivation, opportunity, and ability perspective, $\quad$ J.Clean. Prod. 100 (2015) 224e234.

[80] E.M. Authority, Singapore Energy Statistics, Singapore Government, 2015. http://www.ema.gov.sg/cmsmedia/Publications_and_Statistics/Publications/ses/2015/energyconsumption/index.htm.

[81] P.P.-J. Yang, O.B. Lay, Applying ecosystem concepts to the planning of industrial areas: a case study of Singapore's Jurong Island, $\quad$ J.Clean. Prod. 12 (2004) $1011 \mathrm{e} 1023$.

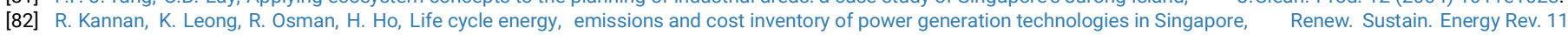
(2007) $702 \mathrm{e} 715$ 